\title{
17 Year Cicada
}

I don't know what wakes me. Why, wingless, I must rise, Only now, only this

Once, pale and larval Out of the ground Into the easy air

The way the sweet sap Of the root that fed me All my seventeen years

Rises spring after spring, Grasses

And the wavering leaf

Reborn.

All around me the soft bodies Of my sisters and brothers Harden in the sun.

Their skins fall from them.

They are the thousand husks

The wind clatters

Through the grasses,

And we are flying on new wings, Sheer, the color of sky, And now we are the sky,

We darken the sun, We sing the wind Its new song,

We shadow the earth,

We fill its stems

With the gifts

Of our eggs,

And then,

We fall.

Kathryn Winograd

\section{Concerned about:}

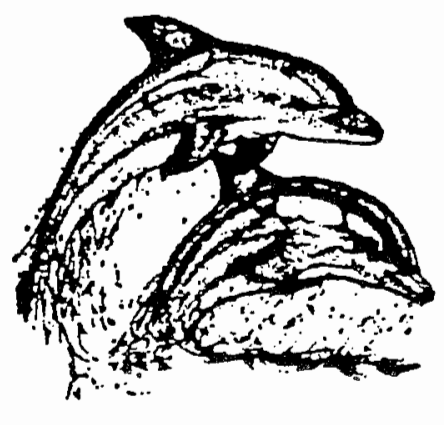

Furs?

Zoos?

Hunting?

Trapping?

Vivisection?

Factory Farming?

Wildlife Conservation?

\section{WE ARE TOO....}

Did you know that philosophers have also made a contribution to the growth of the animal liberation movement?-Think of Clark, Magel, Regan, Rollin, Singer and Sapontzis.

Between the Species "is the only publication which allows such extensive examination of the philosophical basis for animal rights."- Brad Miller, Humane Farming Association.

Subscribe today - and please send your tax deductible contribution - help us guarantee philosphers a forum in which to continue to evolve a sound basis for animal rights.

\section{$\$ 16.00$ from:}

Between the Species

P.O. Box 8496

Landscape Station

Berkeley, CA 94707

Sample back issue $\$ 3.00$

PHILOSOPHICAL ACTIVISM

NEEDS YOUR SUPPORT! 